\title{
Do Member States Grant State Aid When They Act as Regulators?
}

\author{
Phedon Nicolaides*
}

When Member States act as regulators, they need not maximise revenue from the granting of permits, licences or concessions rights. However, they must grant permits, licences or concession rights on the basis of procedures which are open, transparent, non-discriminatory and unconditional. This article argues that qualitative selection criteria may not in fact support the effective achievement of the stated regulatory objectives and, as a result, they may confer an advantage and transfer State resources to the chosen undertakings. Since the concept of State aid does not depend on policy aims or intentions, the regulatory objectives of the authority that grants the exclusive permits, licences or concessions should be irrelevant. EU law does not prevent Member States from using procedures that can aim simultaneously at revenue maximisation and achievement of public policy objectives.

Keywords: Competitive Selection; Regulation; Non-Discrimination.

\section{Introduction}

An established principle in the case law on State aid is that when Member States grant concessions for the exploitation of public assets they should award the contract to the highest bidder or to the bidder that makes the economically most advantageous offer. Otherwise they forgo potential revenue, for a given level of quality of service, and they end up granting State aid to the concessionaire. ${ }^{1}$

But must Member States also aim to maximise revenue from the granting of concessions or other operating rights when they exercise their regulatory powers? The answer given by the Court of Justice is that they are neither precluded, nor obliged to do so. They may choose an operator on the basis of a procedure that does not seek to maximise revenue. Indeed, criteria other than revenue can be used, as long as they are applied in a non-discriminatory manner and are suitable for the purpose of the regulation.

When the State does not act as a regulator, the case law requires that the highest bidder is chosen, not only because I this way the State does not forgo any revenue, but also because the bidder that can afford to make the highest bid is the most efficient. Hence, if the most efficient bidder wins the concession, it follows that it derives no advantage that it would not have been able to obtain under normal market conditions (i.e. in the absence of State intervention).

Hence, the question that arises in connection to the granting of concessions or operating rights in situations where the State acts as a regulator is whether the efficiency of the chosen operator can be disregarded. Presumably the efficiency of any operator can be disregarded if efficiency is not relevant to the aim of the regulatory regime that is being enforced. For example, doctors pay a licence fee and are authorised to practice according to their knowledge and training, not according to how many patients they can process.

However, when the selection process affects competitive conditions between competitors that fulfil all the quality requirements, as set by the relevant regulation, can their efficiency be disregarded? This

DOI: $10.21552 /$ estal/2018/1/3

* Phedon Nicolaides, Professor at the College of Europe and University of Maastricht. I am grateful for comments on previous versions by Péter Staviczky and Katri Paas-Mohando. The two case studies included in this article were first published on the Lexxion blog "State Aid Uncovered" (StateAidHub.eu), available at < http://stateaidhub.eu/blogs/stateaiduncovered/post/9114> and <http://stateaidhub.eu/blogs/stateaiduncovered/post/9115> (last accessed on 4 February 2018).

1 See section 7.3, "aid to operators", of the Commission Notice on the Notion of State Aid, OJ C262, 19/7/2016. 
question is especially pertinent to the granting of rights to exploit State assets that generate revenue for the operator. Here efficiency matters and can be decisive in determining who secures the right to exploit them. Therefore, a selection procedure that maximises the price offered to the State (i.e. the concession fee) in fact forces competitors to reveal their efficiency and, therefore, their ability to use more effectively the State asset. Moreover, efficient use of State assets can very well be a relevant regulatory objective.

It is a fundamental principle of State aid law that State aid is an objective concept and, therefore, Article107(1) TFEU does not distinguish between measures of State intervention by reference to their aims or motives, but according to their effects ${ }^{2}$ and independently of the technique of intervention. ${ }^{3}$

The purpose of this article is to show, first, that the use of qualitative selection criteria can be "objective" but unrelated to the purpose of the avowed regulatory objective and, second, to argue that ignoring revenue maximisation can distort competitive conditions between competitors and can also lead to manipulation of the selection process. This is because in the case of exploitation of State assets, reliance solely on qualitative selection criteria may lead to inefficient exploitation. This implies that the chosen

2 See C-487/06 P British Aggregates v Commission [2008] ECLI-757, [85].

3 See C-279/08 P Commission v Netherlands [2011] ECLI-511, [51].

4 See, C-379/98 PreussenElektra [2001] ECRI-2099; C-72/91 Sloman Neptun Schiffahrts [1993] ECLI-97.

5 The case law on State aid and public procurement is well summarised in the following documents and articles: D Hughes, The Inter-relationship between the European State Aid and Public Procurement Rules: When does a government contractor gain an economic advantage? (Maastricht: EIPA 2009); European Commission Staff Working Document, Guide to the application of the European Union rules on state aid, public procurement and the internal market to services of general economic interest, and in particular to social services of general interest, SWD(2013) 53 final, 29 April 2013; European Commission, Notice on the notion of State aid as referred to in Article 107(1) TFEU, OJ C262, 19 July 2016; P Nicolaides and S Schoenmaekers, 'Public Procurement, Public Private Partnerships and State Aid Rules: A Symbiotic Relationship' (2014) 1 European Procurement \& Public Private Partnership Law Review, 50-69; P Nicolaides and S Schoenmaekers, 'The concept of 'advantage' in state aid and public procurement and the application of public procurement rules to minimise advantage in the new GBER' (2015) 1 European State Aid Law Quarterly, 143-156; A Sánchez-Graells, 'Public Procurement and State Aid: Reopening the Debate?' April 2012, available at SSRN: <https://ssrn.com/abstract=2037768> (last accessed on 4 February 2018); S Schoenmaekers et al. (eds), State Aid and Public Procurement in the European Union, (Cambridge: Intersentia 2014). operator enjoys an advantage it would not otherwise have obtained under normal market conditions. This article also indicates how Member States can achieve their regulatory objectives and maximise revenue at the same time.

The article is organised as follows. The next section reviews the meagre case law that exists on the regulatory acts of the State in connection to Article 107(1) TFEU and places the problem in the wider context of competitive selection of operators. Section III considers whether it is possible for Member States to use a combination of qualitative and quantitative selection criteria when they act as regulators. Sections IV and V illustrates the challenge of pursuing regulatory objectives without revenue maximisation with the use of two case studies based on recent Commission decisions. Such cases are rare. Section VI develops a simple model to demonstrate how qualitative criteria may be manipulated by bidders and argues that revenue maximisation is compatible with the achievement of regulatory objectives. The concluding section VII summarises the main points of the article.

\section{Competitive Selection and Case Law on the Regulatory Behaviour of the State}

It is clear from the case law that regulatory acts are not State aid, because they do not normally entail transfer of State resources, nor do they confer an advantage because they are supposed to be applied in a non-discriminatory manner. ${ }^{4}$

It is also clear from the case law that competitive selection of undertakings to which special or exclusive rights are conferred does not constitute State aid in their favour because in this instances too they derive no advantage. The fee they pay when they obtain the right to exploit an asset, corresponds to the market rate. The same holds for the price they receive, whenever they obtain the right to provide goods or services to the State.

Therefore, we need to understand, first, how competitive selection and the application of public procurement rules interact with State aid rules before considering how selection in a regulatory situation differs. The interface between public procurement rules and State aid rules can be summarised in three statements. $^{5}$ 
First, unless explicitly required by secondary legislation, a public authority that acts as a private investor is free to choose its partners, provided that the project in which it invests is shown on an ex-ante basis to be capable of generating a return that can satisfy the typical market investor. In case a public entity co-invests with a private investor on pari passu terms it is presumed to be acting in conformity with the market economy investor principle.

Second, compliance with public procurement rules does not necessarily ensure that no advantage is granted in the meaning of Article 107(1) TFEU. This is because of at least three reasons: 1) A contract may fall below the thresholds defined in the public procurement directives. 2) The contract may be awarded without competition to an in-house operator who may still derive an undue advantage. 3) Other exceptions of the public procurement directives may be applicable. For example, in sectors such as network industries [e.g. postal services] where there may be only one operator, they permit the granting of a direct award without prior competitive selection.

Third, non-compliance with public procurement rules or non-use of tendering procedures does not necessarily confer an advantage in the meaning of Article 107(1) TFEU. For example, the public authority concerned may be able to calculate correctly the market price and award a contract or sell an asset at the right market price without first having to organise a competitive procedure. This may be practically difficult, but theoretically it is not impossible, if credible benchmarks of market price are available.

However, as an empirical statement rather than principle of law, a defective procurement or sale procedure is likely to result in the granting of State aid for a number of reasons. First, a procedure for the purchasing of goods or services that excludes potential bidders may result in a higher price paid by the procuring authority. Some of the excluded bidders may be willing to supply at a lower price. This confers an undue advantage to the winner and also results in an excessive transfer of State resources. Similarly, adjustment of contracts after they are awarded may also confer an advantage, if the adjustment reduces the costs that the winner was expecting to bear before the award was made.

Second, a procedure for the sale of services or public assets that excludes potential bidders may result in a lower price obtained by the selling authority. This is because some of the excluded bidders may be will- ing to offer a higher price. As a result, the winner obtains an advantage, while the selling authority forgoes potential revenue that is equivalent to transfer of State resources in the meaning of Article 107(1) TFEU.

In the former case, the public authority acts as a private buyer, while in the latter case the public authority acts as a private seller or vendor. The behaviour of the hypothetical market operator defines a benchmark against which it is determined whether procurement or competitive selection procedures confer an advantage.

But what happens when a public authority acts as a regulator rather than a market operator? What benchmark can be used to determine whether it behaves in a way that a regulator should behave? Indeed, how is a regulator supposed to behave? Can a "regulator" benchmark be defined?

When the State acts as a regulator, by definition, it seeks to achieve a public policy objective. The selection criteria that must therefore be used should be those that are the most suitable to achieve that objective. In other words, the objective determines the criteria. Admittedly, the most suitable criteria may not always easy to define. Expert opinion can differ. It follows that Member States should have a certain degree of discretion in defining such criteria. But, at minimum, the State should explain why the criteria it chooses are appropriate and it must treat equally all those who are in the same situation. This normally stems from the purpose of regulation itself, which is to remedy a market failure or pursue a certain public policy. If the selection criteria are applied unevenly, or in a discriminatory manner, they will not constrain or incentivise equally all potential operators and, consequently, they will not achieve fully the aims of the regulation.

What happens, however, when there is a mixed situation such as when the regulatory act or decision involves the charging of a fee? For example, in order to obtain a licence to practice medicine or to broadcast or to operate a bank, it is normal to pay a fee. In these cases the purpose of the fee is merely to cover the administrative costs of the issuing of the licence. In some regulated industries such as banking or telecommunications, the fee is also intended to cover the costs of the regulatory body. That is, all of the expenses of the regulator, not just those linked directly to the issuing of licences, are borne by those it regulates. 
Again, in this situation, the fee has to be the same for all regulated undertakings which are in the same situation. The fee does not have to be a fixed absolute amount. It may also be proportionate to the size of the undertaking. This is how, for example, banks or insurance companies contribute to the costs of the regulator. But still all undertakings pay the same relative fee.

In none of the above situations is the competitive position of the regulated undertakings vis-à-vis each other negatively affected.

But there is another situation that raises important questions concerning the amount of the fee that should be charged. This situation concerns permits to operate certain assets at the exclusion of other undertakings or permits to operate in a certain region or certain sector at the exclusion of other undertakings. The fee in this case can have three purposes: 1 ) to cover administrative costs, 2) to determine who gets the right to operate or exploit the asset (by assigning that right to the highest bidder) and 3) to generate revenue for the State from the profits that the permit holder can eventually earn from the commercial exploitation of the asset. A competitive selection would normally ensure that the second and third purposes would be achieved simultaneously. The winner would be the company to offer the highest fee to the authority granting the permit, while the fee would be determined by the amount of the expected future profits. The company that would be the most efficient in exploiting the asset would presumably be the one that would offer the highest fee. This is the practice for the allocation of scarce resources such as the radio spectrum or the right for oil exploration where the operation of one undertaking excludes the simultaneous operation of another.

In a situation of exclusionary permits, licences or concessions, the competitive position of different operators is necessarily affected. The operator that manages to secure the permit, licence or concession at the exclusion of others does not derive an advantage only when it pays a market price. And a market price is the price that is the outcome of an open, transpar-

6 Here the Notice cites case T-475/04 Bouygues v Commission [2007] ECLI-196, [104].

7 Here the Notice cites cases T-475/04 Bouygues v Commission [2007] ECLI-196, [108-111, 123]; C-431/07P Bouygues and Bouygues Télécom v Commission [2009] ECLI-223, [94-98, 125]; C-518/13 Eventech v The Parking Adjudicator [2015] ECLI-9 [46] et seq. ent and non-discriminatory selection that awards the right to the most efficient operator that fulfils all the relevant qualitative requirements. If there is a tradeoff between price and quality, then the winner is the one who makes the economically most advantageous offer.

It follows that in situations of exclusionary permits, if the State does not award operation or exploitation rights to the highest bidder, it may confer an advantage in the meaning of Article 107(1) TFEU and forgo potential revenue. Assuming that the other conditions of Article 107(1) TFEU also hold, the use of criteria that do not include revenue maximisation is likely to constitute State aid.

However, as the case law currently stands, Member States are not obliged to establish an auctioning process or any other competitive selection method that can maximise revenue whenever they act as regulators in pursuit of public policy objectives. EU case law neither requires them, nor prevents them from maximising revenue.

This is how the Commission describes the relevant case law in its Notice on the Notion of State Aid. "(53) Granting access to a public domain or natural resources, or granting special or exclusive rights without adequate remuneration in line with market rates, can constitute foregoing State revenues (as well as the granting of an advantage)." "(54) In these cases it needs to be established whether the State, in addition to its role of manager of the public assets in question, acts as a regulator that pursues policy objectives by making the selection process of the undertakings concerned subject to qualitative criteria (established ex ante in a transparent and non-discriminatory manner). ${ }^{6}$ When the State acts as a regulator, it can decide legitimately not to maximise the revenues which could otherwise have been achieved without falling under the scope of State aid rules, provided that all the operators concerned are treated in line with the principle of non-discrimination, and that there is an inherent link between achieving the regulatory purpose and the foregoing of revenue." "(55) In any event, a transfer of State resources is present if, in a given case, the public authorities do not charge the normal amount under their general system for access to the public domain or natural resources, or for granting certain special or exclusive rights."

The judgment in case C-518/13, Eventech $v$ The Parking Adjudicator, concerned the use of bus lanes in London by black taxis but not mini cabs. 
The Court of Justice began with the following observation. "(47) It must however be stated that that question (...) concerns whether the bus lanes policy, by which TfL [Transport for London (the relevant regulator)] pursues the objective laid down by the State legislation, namely to ensure a safe and efficient transport system, must be regarded as conferring on its beneficiaries an economic advantage, for the purposes of Article 107(1) TFEU, which falls within the scope of EU law on State aid and which has an economic value which must be paid for by those beneficiaries."

"(48) In that regard, (...), it must be held that where the State, in order to pursue the realisation of an objective laid down by that State's legislation, grants a right of privileged access to public infrastructure which is not operated commercially by the public authorities to users of that infrastructure, the State does not necessarily confer an economic advantage for the purposes of Article 107(1) TFEU."

"(49) Further, it must be stated that the identification of the objective pursued is, in principle, a matter within the prerogative of the competent national public authorities alone and they must have a degree of discretion both as regards whether it is necessary, in order to achieve the regulatory objective pursued, to forgo possible revenue and also as regards how the appropriate criteria for the granting of the right, which must be determined in advance in a transparent and non-discriminatory manner, are to be identified."

But in a previous case, T-475/O4, Bouygues $v$ Commission, concerning the award of licences to telecoms operators, the General Court seemed to suggest that any fee that is charged should correspond to the "economic value" of the licences in combination with other criteria which were linked to public policy objectives.

The General Court noted that "(104) the exercise of State functions does not preclude the taking into account of economic facts in connection with the management of a scarce public resource such as the radio frequencies constituting the public airwaves, to which a right of access or a right of usage may be granted. Hence, the Member States simultaneously perform the roles of telecommunications regulator and manager of the public assets that constitute the wireless airwaves."

It then went on to recall that "(108) the Community framework for telecommunications services, (...), rests on equality of treatment between operators for the award of licences and the calculation of any fees and leaves the Member States free to choose the procedure for the award of licences, provided that the principles of freedom of competition and equality of treatment are respected. Hence, although the Member States may use public auctions, they may equally opt for a comparative selection procedure, as in the present case, the essential point being that the operators see that they are accorded the same treatment, in particular as regards fees."

"(109) To that effect, (...) the fees charged to different operators must be equivalent in economic terms. Furthermore, having noted that the setting of fee amounts involves complex economic assessments and that the national authorities could therefore not be required to comply with rigid criteria in that regard, provided that they remain within the limits resulting from Community law, the Court stated that the national court must determine the economic value of the licences concerned, taking account inter alia of the size of the different frequency clusters allocated, the time when each of the operators concerned entered the market and the importance of being able to present a full range of mobile telecommunications systems".

"(110) Hence, although the right to use the wireless space granted to the operators has an economic value, the amount payable as a fee can constitute State aid only if, all other things being equal, there is a difference between the price paid by each of the operators concerned, it being recalled that, according to the Court of Justice, it is the time when each of the operators concerned entered the market that must be taken into account ... . On the other hand, if the national authorities decide as a general principle that licences will be awarded free of charge, or awarded by means of public auctions or awarded at a standard price, there is no aid element, provided these terms are applied to all the operators concerned without distinction."

"(111) Consequently, the fact that the State may have waived resources and that this may have created an advantage for the beneficiaries of the reduction in the fee is not sufficient to prove the existence of a State aid incompatible with the common market, given the specific provisions of Community law on telecommunications in the light of common law on State aid. The abandonment of the claim at issue here was inevitable because of the general scheme of the system". 
It is not clear why, in this context, the Commission Notice refers to case C-431/07 P, Bouygues and Bouygues Télécom v Commission. When, on appeal, the Court of Justice reviewed the judgment of the General Court, it merely observed in paragraphs 94-98 and 125 that, given the conditions under which telecoms licences had been awarded, France had to align the fees paid by the various telecom operators so as to avoid distortion of competition. The Court of Justice did not deal with the behaviour of the State as a regulator. In fact it endorsed a fee-setting method that prevented distortions to competition. The point of view of this article is that competition may in fact be distorted if fees are set by methods that do not maximise revenue.

Three principles may be inferred from the judgment of the General Court in Bouygues and the Court of Justice in Eventech. First, when Member States act as regulators to allocate rights that have economic value do not have to auction those rights. Second, they may take into account public policy objectives or impose on those to whom they grant the rights certain obligations in line with public policy objectives. Third, they do not need to charge fees or, if they charge any, they may not aim to maximise revenue.

However, given the fact that they are not precluded from maximising their revenue, should Member States not seek to maximise the revenue they can obtain when they put public assets at the disposal of private operators? Competition with respect to the fee that bidders pay should create benefits through cost efficiency and innovation, even when a single company gains the right to operate on the market. Exploitation of consumers by a potential monopolist can be prevented through price regulation. At the same time, if the winner is the one who pays the highest fee, then it has a strong incentive to make profit by reducing its costs and become more efficient. This does not mean that qualitative criteria and public policy objectives should be disregarded. They can very well be taken into account when designing the selection process or they can be incorporated in the contractual obligations of the selected operators. The selection process, for example can be carried out in two stages. In a first stage, operators who meet qualitative criteria are selected, while in a second stage, the qualified operators submit price offers.

Regardless of whether a Member State adopts a two-stage procedure or incorporates qualitative re- quirements in the permits it issues or the concessions it awards, it is hard to see how the most effective utilisation of the public asset can be achieved when the selection process does not incentivise the selected operator to be efficient. This is because it is hard to think of a legitimate public policy objective that does not seek to maximise the benefits to society from the use of a public asset.

\section{Benchmark of Regulatory Behaviour}

When the State claims that it acts as a market economy operator (MEO), it must prove it by showing how it intends to maximise the return it hopes to obtain. Otherwise, it will end up granting State aid to the company to which it awards the right for the exploitation of a State asset.

When the State claims that it acts as a regulator, how can it prove it? In situations where it does not place a revenue-generating asset at the disposal of a company, the application of objective criteria and the charging of an administrative fee should be sufficient. This is because objective criteria are non-discriminatory and a fee that reflects administrative costs does not advantage or disadvantage any competitor. In this case, the selection procedure necessarily has to rely on qualitative criteria which must be suitable for the achievement of the regulatory objective. The regulatory objective determines the nature of the selection criteria.

When, by contrast, the State awards rights to a revenue-generating asset, but at the same time it claims it acts as a regulator, can it dispense with revenue maximisation and rely instead on other criteria? For sure in a purely accidental case only can the right be granted to the company that is able to generate the largest amount of revenue. And, almost certainly, the right will be awarded without the State being able to maximise the revenue that it could potentially raise. In the second case study in this article, the Commission claimed that it was not necessary for the State to maximise its revenue because it was acting as a regulator. The Commission also found that the other selection criteria were applied in a nondiscriminatory manner and were capable of choosing the company that maximised "benefits" for the State.

Therefore, the crux of the issue is whether criteria that exclude revenue maximisation and therefore ig- 
nore the efficiency of the various competitors can be applied in a truly non-discriminatory way. The penultimate section of this paper argues that, in situations where only one or a few undertakings can operate, it appears impossible to apply the qualitative criteria in a non-discriminatory manner by ignoring the efficiency of the chosen operator.

Whether qualitative selection criteria are discriminatory depends on whether they are suitable for the regulatory objective at hand. If the objective is the effective utilisation of an asset, then any criterion other than the revenue that can be generated from that asset is an imperfect substitute or proxy. This is because revenue takes into account the ability of the company to use the asset as effectively as possible.

Naturally, there can be other criteria, such as sustainable use of the asset, which would imply that the revenue from it is maximised over a longer rather than shorter period. Another criterion could be prevention of environmental degradation. Compliance with this criterion would translate into higher operating costs which would mean that the revenue maximisation would occur after a certain level of environmental protection is achieved. A third criterion may be open access to the public. In this case, the operator of the asset would have to maximise both the number of users and revenue and find the right tradeoff. A properly designed competitive selection procedure can combine such qualitative criteria together with efficient use of the asset. These examples suggest that other criteria do not force the operator that acquires the rights to the asset to forgo profit maximisation but merely require it to take them into account as well. The chosen operator must be both efficient and able to meet the performance targets set by other, qualitative criteria.

The important point to note from the above examples is that efficient use of the public asset supports the other criteria. Let's consider the typical public policy objective of preventing environmental degradation. It is reasonable that a government that awards, for example, rights to mineral extraction would want to do so at the least possible damage to the environment. Let's say that for every ton of extracted mineral, there is $\mathrm{X}$ damage to the environment. An efficient company can cover its costs by extracting $\mathrm{Y}$ tons while an inefficient company needs $2 \mathrm{Y}$ tons to cover its costs. It follows that the inefficient company causes more damage to the environ- ment because $2 \mathrm{YX}>\mathrm{YX}$. Moreover, a more efficient company may also be able to cause less environmental damage per ton of extracted mineral.

Can the same reasoning be applied to situations in which the regulatory intervention of the State imposes limits on the presence of competitors on the market but otherwise treats them equally and charges all of them the same fee, as in the first case study in this article? The only difference between undertakings in this case is that one undertaking is allowed to operate more branches because it is obliged to provide training to students and develop certain services and products. However, to the extent that not all additional branches are necessary for the training or product development, the favoured undertaking derives a commercial advantage. It pays the same fee but operates more branches than others. By not charging a higher fee that corresponds to the value of extra branches, the State allows that undertaking to enjoy an advantage and at the same time it forgoes potential revenue that is equivalent to transfer of State resources. The fact that the State charges the same fee to all operators is irrelevant because some of the additional branches are no longer necessary for the achievement of regulatory objectives.

Three conclusions may be drawn from the preceding considerations. First, it is worth reiterating that, unless required by specific EU law, Member States are free to determine their own policy and regulatory objectives. However, if they claim that they act as regulators when they allocate rights to scarce resources, they must also demonstrate how the selection criteria they use are suitable for achieving those objectives. Second, the efficiency of the operator, as expressed into ability to generate net revenue, is an indispensable criterion on its own or in combination with other selection criteria. Since wasteful use of a public asset cannot be a public policy objective, efficient use of the asset can be inferred to be a policy objective, regardless whether it is explicitly defined as such. Third, efficient use of the public asset supports any other qualitative criteria and policy objectives.

The following case studies demonstrate the dilemmas confronting Member States when they decide to choose the right selection procedure in exercising their regulatory powers. As it will become obvious, operating efficiency was not one of the public policy objectives. 


\section{Case Study I: Commission SA.42028 Concerning Licencing of Yliopiston Apteekki Oy in Finland ${ }^{8}$}

Yliopiston Apteekki Oy is a pharmacy owned by the University of Helsinki (hereinafter UHP). A complainant alleged that UHP was allowed to operate more branches than other pharmacies and that it benefitted from a tax refund. This article considers only the issue of the number of branches and the related licence fee.

In Finland there is a system for licensing pharmacies. The Finnish Medicines Agency (FIMEA) may authorise licensed pharmacists to keep up to a maximum of three branches. However, UHP is allowed to keep up to sixteen branches. Licences to operate a branch pharmacy are granted on payment of a fee to cover administrative costs. In 2015 the fee was $€_{2500}$ per application. The fee was paid by any pharmacy that applied for a licence to operate a branch.

Finland claimed that it acted as a regulator aiming to protect public health. UHP was allowed to operate up to sixteen branches because it was required to provide practical training to students of pharmacology, to develop pharmaceutical services and to produce rare medications.

\section{Existence of State Aid}

With respect to the licences, the Commission considered that there was no loss of State resources. The Commission first noted that "(32) granting special or exclusive rights without adequate remuneration in line with market rates can constitute foregoing of State revenues (as well as the granting of an advantage). At the same time, when the State acts as a regulator, it can decide legitimately not to maximise the revenues which could otherwise have been achieved, without falling under the scope of State aid rules. ${ }^{9}$ In

8 The full text of the Commission decision can be accessed here: <http://ec.europa.eu/competition/state_aid/cases/271830/271830 _1941545_17_3.pdf> (last accessed on 4 February 2018).

9 At this point the decision cited the judgments case C-518/13 Eventech v The Parking Adjudicator [2015] ECLI-9 [47-48]; C-431/07P Bouygues and Bouygues Télécom v Commission [2009] ECLI-223, [110].

10 At this point it cited the opinion of General Advocate Wahl in the Eventech case, paragraph 32.

11 The excerpt is from the following judgment: C-518/13 Eventech $\mathrm{v}$ The Parking Adjudicator [2015] ECLI-9 [49]. doing so, however, the State must "act in a genuinely regulatory capacity". ${ }^{10}$

It continued that "(33) when issuing licences to UHP as well as to private pharmacies, Finland regulates and limits access to the Finnish pharmacy market. It is clear that Finland does not commercially exploit its position as regulator by "selling" licences to operate a (branch) pharmacy at market price. Rather, the licences are granted to both UHP and private pharmacies alike, without demanding a consideration corresponding to the economic value of the licences. The regulating authority FIMEA merely charges a uniform fee to cover the costs it incurs in processing licence applications. Whether the State would receive the licence fees from UHP or from any other company would not make a difference for the State budget. In addition, despite the fact that a licensed pharmacist may keep up to maximum three branch pharmacies, the overall number of (branch) pharmacy licences that can be granted country-wide in Finland is not limited; rather, licences can be granted as long as the conditions set out in Section 52 of the Medicines Act are fulfilled."

The meaning and implications of the last sentence of this paragraph are not obvious.

The Commission went on to explain that "(34) it must be assessed whether the decision of the Finnish authorities not to charge UHP for its exclusive right is inherently linked with the policy objective behind that exclusive right. In this regard, the European Court of Justice observed that 'the identification of the objective pursued is, in principle, a matter within the prerogative of the competent national public authorities alone. They must have a degree of discretion both as regards whether it is necessary, in order to achieve the regulatory objective pursued, to forgo possible revenue and also as regards how the appropriate criteria for the granting of the right, which must be determined in advance in a transparent and non-discriminatory manner, are to be identified. ${ }^{, 11 "}$

It is important to note that in the Eventech case which concerned the use of dedicated bus lanes by London black cabs, the responsible authority, Transport for London, did not charge any fee to any taxi company. Mini cabs [i.e. not black cabs] were simply not allowed to use bus lanes. Nor, was there in London any differentiation in terms of access to market as in Finland where UHP was allowed to operate more pharmacies. Therefore, the question that arises is whether there can be differentiated access ac- 
cording to criteria which are set "in advance in a transparent and non-discriminatory manner". In principle, the answer can be in the affirmative as long as the differentiation is linked to the achievement of the regulatory objectives defined by the Member State concerned. But, as I will argue below, in Finland there was no precise link between the number of extra branch licences available for UHP and regulatory objectives. That meant that UHP enjoyed wider market access and, although every undertaking paid the same of $€_{2500}$ per branch or pharmacy, in reality the State lost the revenue that it could have obtained, had it allowed all pharmacies to open up to 16 branches, or had it charged UHP for the value of the extra branches that were not necessary for the achievement of Finland's regulatory objectives.

Then the Commission examined whether Finland applied transparent and non-discriminatory criteria. "(35) First, the Commission notes that the objectives and tasks of the branch pharmacy system were laid down in the Medicines Act and in the works preceding it, so that the criteria were therefore established in a transparent manner."

"(36) Second, the Commission recalls that the overarching objective of the Medicines Act is to protect public health, in particular to maintain and promote the safety of medicinal products and their use and appropriate use of pharmaceuticals. UHP has certain specific tasks, laid down in Section 42(1) of the Medicines Act, pursuant to which UHP has to provide practical training in connection with pharmacy teaching and to conduct research on pharmaceutical services. Additionally, UHP has the obligation to manufacture certain rare pharmaceutical preparations, as mentioned in the rationale for the Medicines Act. As the judgment of Finland's Supreme Administrative Court confirmed, when processing an application by UHP to open a branch pharmacy, FIMEA needs to consider whether that branch actually contributes to the fulfilment of UHP's specific tasks."

"(37) Third, the CJEU had already the opportunity to declare that a logical connection exists between the objectives of the Medicines Act, the special tasks of UHP and the pharmacy right of UHP. According to the CJEU, a system like the current one is required to carry out the special tasks of UHP, as far as its branch pharmacies participate in the realisation of the special tasks ${ }^{12}$."

"(38) Concretely, (...) all UHP branches provided practical training to pharmacy students (...); (ii) (...)
UHP pharmacists also get involved in teaching activities within the University of Pharmacy and that UHP has also financed and participated in the organisation of research and advanced studies in pharmacy and related disciplines; (iii) (...), UHP is the sole producer of a number of rare medicines in Finland; it manufactures certain life-saving pharmaceutical products that are not manufactured by the industry and would not be available from other sources."

"(39) In this context, the Commission considers that the Finnish authorities could reasonably take the view that charging UHP for the right to maintain up to thirteen branches more than private pharmacies might jeopardise the achievement of the objective, at least in part, since it might deter UHP from opening or maintaining branch pharmacies."

The conclusion of the Commission in paragraph 39 of its decision is tenuous and disputable. It is tenuous because it does not follow from the objectives of the Finnish licensing system that UHP needed up to 13 extra branches to carry out the tasks assigned to it. It is worth noting that in the case of services of general economic interest, when a Member State imposes a public service obligation on an undertaking, that obligation must be "necessary" and "proportionate". ${ }^{13}$ By analogy, when the State acts as a regulator, the regulatory obligations and requirements must also be necessary and proportionate. With respect to the fee, if it is linked to the administrative cost of the regulator who presumably has to ensure that each new pharmacy is properly equipped and staffed to meet public health standards, then UHP must necessarily pay the fee for each new branch it opens. But if some branches are not necessary for achieving the objectives of the Finnish system, then the State should be charging a fee that corresponds to their commercial value.

The Commission's conclusion is also disputable because whether UHP would be capable of paying for the right to open 13 extra pharmacies was an empirical issue that was not verified (or to be more precise, there was no evidence in the decision that UHP could not afford it). But as a matter of economic principle, if UHP could operate extra pharmacies prof-

\footnotetext{
12 At this point the decision cites the judgment in case C-84/11 Susisalo [2012] ECLI-374, [41-42], which concerned the interpretation of Article 49 of the Treaty on the right of free establishment.

13 See judgment of the General Court in case T-454/13, SNCM v Commission, paragraphs $133 \& 134$.
} 
itably, then by definition a fee could be set, perhaps very small, that it could afford to pay.

\section{Selectivity}

Then the Commission argued that UHP and other pharmacies were not in the same legal and factual situation, something that, in its view, justified different treatment. "(40) Fourth, given that UHP is subject to specific obligations laid down in the law, this differentiates it from the private pharmacies operating in Finland. UHP can thus not be said to be in a comparable legal and factual situation with private pharmacies in Finland, which are not subject to such obligations. This conclusion is in line with the findings of the Court of Justice in its judgment in Case C-84/11 14."

"(42) It follows that the system as such does not seek through its objective and general structure to create an advantage through State resources. (...) The higher number of licences that UHP has is inherent to the system which aims at achieving a public policy objective, and cannot be considered to involve State resources."

Indeed, it is true that UHP was under different legal obligations than other pharmacies with respect to training, research and production of rare medicines. But was there a correspondence between the extent of those obligations and the extent of the right to operate 13 extra pharmacies? In other words, was the right of UHP proportionate to its obligations? If it were disproportionate, then UHP obtained an advantage.

The question that arises is whether that advantage stemmed from State resources so that it could be classified as State aid. One may argue that since the State charged a fee for the licensing of the extra branches, it did not forgo any revenue. Moreover, the fee was the same as that charged to all competitors. However, if some of the extra branches were not necessary for the achievement of the public policy objectives mentioned in the Commission decision, the State granted exclusively to UHP a right that had commercial value. The State does not have to maximise rev-

14 This is the Susisalo case cited earlier: C-84/11 Susisalo [2012] ECLI-374.

15 The full text of the Commission decision can be accessed at: <http://ec.europa.eu/competition/state_aid/cases/268864/268864 _1938168_112_2.pdf> (last accessed on 4 February 2018). enue when it regulates. But in this case, the State went beyond its regulatory remit. Assuming that in this case the regulatory scope was disproportional, the State did forgo potential revenue if the extra branches were worth more to UHP than the three branches allowed for other pharmacies. Hence, the mere fact that the fee charged was the same for all is not enough. A uniform fee is a regulatory instrument if it is used in a non-discriminatory manner. This happens when all competitors are granted the same rights.

However, the Commission did not share this view. According to the Commission, "(43) by granting more than three licences to UHP, the State does not forego state resources. In fact the same applicable fees for the additional thirteen licences as for the up to three licences granted to private pharmacies have been applied. Thus if it had granted those licences to the latter, no higher fees could have been obtained by the Finnish State." This is an irrelevant and hypothetical argument. If Finland would allow private pharmacies to operate up to sixteen branches no discrimination would exist. The relevant issue is that they were not allowed to operate more than three branches and no one knows what Finland would have done had they been permitted to operate more than three branches.

The overall conclusion of the Commission was that there was no loss of revenue from the licensing system and no advantage from the refund of taxes to the University of Helsinki. Therefore, no State aid was involved in these two measures.

However, as I have argued, the number of branches operated by UHP may have been disproportional in relation to Finland's regulatory objectives. UHP was obliged to maintain extra branches for educational reasons. Notwithstanding the validity of those reasons, UHP obtained an advantage, as Article 107(1) TFEU applies to public measures in relation to their effects, not their policy aims.

\section{Case Study II: Commission Decision SA.41116 Concerning the Granting of Exploration Rights to the Polish Company KGHM Polska Miedź ${ }^{15}$}

In February 2015, Darley Energy Poland (DEP) complained to the Commission that Poland had granted State aid to KGHM Polska Miedź (KGHM). According to DEP, Poland had awarded KGHM a concession for the exploration of potash deposits without a com- 
petitive procedure. DEP contended it could make a better offer.

KGHM was at that time one of Poland's biggest companies, Europe's second biggest copper producer and the world's biggest silver mining company. About $32 \%$ of its shares were held by the State.

The Commission decision, in paragraphs 16-23, describes the legal framework in Poland for awarding exploration and exploitation rights. Exploration and exploitation of mineral deposits in Poland can be conducted only after obtaining a concession. The concession is granted by an administrative decision of the Ministry of Environment. The process of granti$\mathrm{ng}$ a concession is initiated either on the basis of an application by a company or a competitive procedure launched by the Ministry which in this case is also the concession authority.

When a company applies for a concession, the Ministry follows an administrative procedure to perform a comparative assessment of the applications, whenever several applications are submitted. During this administrative procedure each applicant has access to the applications of the other participants and can at any time modify its own application to make it more competitive. The applications for concession are evaluated on the basis of objective criteria.

A concession gives its beneficiary the exclusive right to carry out the exploration of deposits and a priority to obtain the rights for the exploitation of the deposits. A concession fee for exploration is defined according to a formula expressed as unit price per type of mineral, multiplied by the area under concession. A concession fee for exploitation is also defined according to a formula expressed in terms of unit price, the size of the deposit, and the usage ratio.

\section{Award of the Concession to KGHM}

In paragraphs 24-33, the decision explains the procedure that was followed to award the concession to KGHM. In November 2012, DEP submitted an application for concession for exploration to the Ministry of Environment. The Ministry subsequently received applications for concession for exploration of the same mineral from three other companies, including KGHM. Because the applications covered partially overlapping areas, the Ministry conducted administrative hearings with the aim of reconciling the conflicting interests. The hearings did not lead to any compromise because none of the applicants modified their applications. The Ministry then compared the competing applications. During this procedure each applicant had access to the applications of other participants. The Ministry did not conduct a competitive tender since the whole procedure was not started with a notice published by the concession authority (i.e. the Ministry), but instead began on the basis of applications by the four companies. In October 2014, the concession authority decided to grant the concession for exploration to KGHM.

\section{Existence of State Aid}

The decisive issue here was whether Poland conferred an advantage on KGHM. The Commission first explained which principle it would not apply in this case because the measure concerned the regulatory actions of the State. "(47) Economic transactions carried out by public bodies do not confer an advantage on their counterparts, and therefore do not constitute aid, if they are carried out in line with normal market conditions. Compliance with normal market conditions is normally assessed on the basis of the "market economy operator" (MEO) test, whose purpose is to determine whether with regard to a certain transaction the State acted as a private operator in a similar situation. The MEO test is, however, not applicable in transactions where the State acts as a public authority rather than as an economic operator."

But is this a purely regulatory measure (such as checking the credentials of a doctor or a bank) or is it also about placing State assets at the disposal of an undertaking? If it is the latter, the MEOT should be applied. The Commission went on to note that " $(48)$ under Polish law deposits of potassium salt belong to the State and their exploration and exploitation can be conducted only after obtaining the concession from the State. No market operator can grant any such or similar concession, and, therefore, no market operator can be in a similar situation as the State. In addition, according to Polish law, when evaluating applications for the concession, the State must take into account public interest, security, environmental protection and rational management of mineral deposits. These are legitimate considerations which are relevant for a public authority rather than for an economic operator that is ultimately concerned only with profit maximisation and which, furthermore, 
are not prone to any meaningful quantifiable economic analysis."

Although this line of reasoning seems to be in conformity with the Eventech and Bouygues judgments cited in section II, it is not fully convincing. All the non-economic concerns mentioned above can be formulated into extra requirements that can be contractually imposed on the applicants and eventual concession winner. None of those concerns prevents the relevant public authority from auctioning the rights to the highest bidder after the contracting authority verifies that potential bidders have the necessary qualifications. Indeed typical two-stage procurement procedures achieve both aims: reaching qualitative public policy targets and maximising revenue once those targets are reached. The first stage normally checks compliance with the requirements of public policy, while the second stage contains competitive bidding. In this way competitive bidding does not prevent the achievement of the public policy objectives mentioned in the previous paragraph. It is not the same as the allocation of broadcasting spectrum where it may be contrary to the public interest to assign all frequencies to the highest bidder because it is essential to maintain media plurality. But even in such a case, Member States ration frequencies through a combination of auctioning and quantitative limits on the number of frequencies that may be held by the same company. Similar methods are applied to regional allocation of broadband licences. ${ }^{16}$

The Commission also pointed out to the practice in other Member States, but it is doubtful that the practice in other legal systems is relevant to the assessment of the existence of State aid, given that it is the legal system of the country in question that matters. "(49) The granting of concessions for exploration or exploitation of mineral deposits is, due to its regulatory nature, typically performed by the State in Member States of the Union and can be categorised as the exercise of public authority powers. In view of that, and contrary to the view of the Complainant, the Commission takes the view that in granting the concession for exploration, the State act-

16 For example, two recent Commission decisions concluded that two-stage selection procedures involving qualitative and quantitative criteria were capable of eliminating any advantage for the winners: SA.44259 concerning a concession for the management of 14 Greek regional airports and SA.42545 concerning the operation of Hamburg Congress Centre.

17 Emphasis added. ed as a public authority and, consequently, the MEO test is not applicable."

The implication of this view is that the granting of exploration concessions may not aim to maximise revenue for the State. Not seeking to maximise revenue is clearly understandable in the case of licensing a doctor or bank. The licence is not tradable [i.e. not transferable] and its aim is merely to confirm that the doctor or bank fulfil all necessary requirements for safe or sound operations. The asset is not limited by nature, nor is a State asset put at the disposal of the doctor or bank. But this is not the case here. And in fact the very next paragraph of the decision goes on to admit as much. Nonetheless, it should also be said that the case law does acknowledge that Member States are free to choose whether or not to auction licences or concession rights.

"(50) The granting of the concession for exploration can have an economic value in that it is associated with the priority right to claim exploitation of the minerals which do have an economic value since those minerals are tradeable, and therefore, the concession for exploration may still entail an economic advantage for the concession holder in the present case. Insofar as the mineral resources of Poland are under ownership of the State Treasury, any undue advantage conferred by the concession for their eventual exploitation is to be regarded as involving State resources within the meaning of Article 107(1) TFEU." ${ }^{\prime 7}$

By exploring, KGHM was hoping to find mineral deposits that could be commercially traded. But how are we to understand the meaning of undue advantage when the State is not acting as MEO trying to maximise revenue? In paragraph 51 (which is not quoted here), the Commission rejected the argument of DEP that KGHM obtained an advantage because the concession rights were not awarded on the basis of first come, first served. This is right. The Polish authorities also took into account the merits of the applications of the other three companies, including that of KGHM. But still it is not obvious how to detect the existence of an undue advantage in a procedure such as that used by Poland.

"(52) Considering that there were four competing applicants and given the outcome of the award procedure, the Complainant has failed to show that a different outcome of the award process could have been more beneficial for Poland. The General Court has already ruled that the public authorities of the 
Member State may take into consideration, in the absence of a competitive tender, the comparability of the offers received, whether they are binding in national law and the broader fulfilment of other objectives than the mere sales price for the purposes of adjudicating a sale of land, without the choice of a lower bid unduly favouring and granting an undue economic advantage within the meaning of Article 107(1) TFEU to the preferred bidder. ${ }^{18}$ This conclusion holds true a fortiori in the present case where none of the alternative offers filed by three other applicants were more advantageous than KGHM's, according to the information available, and KGHM has best met the conditions set out by Poland for the award of this concession." ${ }^{19}$

Two comments are in order here. First, the judgment in case T-244/08 which is cited in paragraph 52 of the Commission decision merely says that price is not the only criterion for awarding contracts. Quality and compliance with regulatory (in this case spatial zoning) requirements are also relevant. In other words, the question is whether the Polish procedure awarded the concession to what in this case would correspond to the economically most advantageous offer.

Second, the Commission criticises DEP for not showing how a different outcome would be "more beneficial" to Poland, but it does not define explicitly what "more beneficial" would mean. The last sentence of the paragraph mentions that the offer of KGHM "best met the conditions", i.e. the selection criteria. From this sentence we can infer that no "undue advantage" means that the chosen offer is the one that best meets the selection criteria and this is how a State, acting as a regulator, maximises the benefits it derives from the awarding of rights (because no other applicant could offer a "more beneficial" or better offer). It finds the company that best serves its policy aims.

In other words, if the State is not to confer an advantage in the meaning of Article 107(1) TFEU when it acts as a regulator it must apply objective criteria and choose the applicant that best meets those criteria. But, as in this case where the offers concerned only partly overlapping areas, it is difficult to compare impartially non-identical offers or applications.

The Commission also examined, in addition to the outcome of the award process, whether KGHM was unduly favoured and whether it received an advantage not available under market conditions, within the meaning of Article 107 (1) TFEU. This examina- tion assessed whether the process of granting the concession for exploration was conducted in line with EU principles on public procurement. ${ }^{20}$ The public procurement principles examined by the Commission were the following:

1. Competitive process,

2. Transparent process,

3. Non-discriminatory selection, and

4. Unconditional process.

\section{a) Competitive Process}

According to the Commission, a selection process is competitive if anyone with the right qualifications can participate in it and compete against others.

The Commission noted that under Polish law anyone interested in exploration and eventual exploitation could submit an application to obtain a concession. "(56) The [four] applications ultimately met formal requirements and the concession authority accepted all applicants to be considered in the selection process. (...) Throughout the proceedings each applicant had access to the applications of the other participants of the process." "(57) As regards the allegation of the Complainant that there was no competitive tender formally speaking, the Commission notes that there was no obligation to organise one. According to Polish law, a tender is organised when the granting of the concession is initiated by the concession authority."

Then the Commission made an important clarification about the applicable case law in this situation. "(58) The Complainant argues that there is an ex ante presumption that transactions in violation of the principle of non-discrimination and transparency entail a State aid element, unless it can be proven that the deficiencies in the process did not affect its outcome. In this respect the Complainant invokes the Land Burgenland case, ${ }^{21}$ in which the Court of Justice confirmed the finding of the General Court that where a

18 Case cited: T-244/08 Konsum Nord ekonomisk förening v European Commission [2011] ECLI-732, [66-75].

19 Emphasis added.

20 The decision cites the judgment in case C-518/13 Eventech $\vee$ The Parking Adjudicator [2015] ECLI-9 [48-49]. This part of the judgment refers to the right of a public authority to achieve a public policy objective by forgoing revenue. Its relevance to selection criteria applied to KGHM is not obvious.

21 Joined cases C-214/12P, C-215/12P and C-223/12P Land Burgenland v Commission, judgment of 24 October 2013, ECLI-682, [94]. 
public authority proceeds to sell an undertaking belonging to it by way of an open, transparent and unconditional tender procedure, it can be presumed that the market price corresponds to the highest offer." "(59) The Commission notes first that this case law concerns primarily the outcome of a tender procedure (an undertaking was not sold to the highest bidder) and not the obligation to conduct it as such. Second, the transaction concerned in Land Burgenland consisted in the sale of an undertaking where the State acted as an economic operator whose behaviour could be compared to a private vendor interested in maximising proceeds, whereas the present case concerns the granting of the concession where the State acted as a public authority whose behaviour cannot be compared to a private vendor, as explained in recitals (48)-(49). Thus, the Commission considers that the reference to the Land Burgenland case is inapposite in view of the different facts of the measure at issue. In any event, as further assessed below (recitals (65)-(80)), the Commission considers that the selection procedure was conducted in accordance with the principles of non-discrimination and transparency."

Therefore, non-discrimination and transparency are absolutely necessary, regardless of whether a public authority is acting as a regulator or an economic operator.

The Commission also clarified that "(63) the lack of a formal tender procedure alone does not preclude the selection process from being competitive, as long as potential participants were not unduly restricted from participating in it. There is no evidence that this was the case. The Complainant itself does not question the fact that all interested entities could have participated in the selection process." "(64) Therefore, the Commission considers that the selection process was conducted in a competitive manner."

\section{b) Transparency}

According to the Commission a selection process is transparent when all interested parties are equally and duly informed at each stage.

"(66) The concession authority informed all the applicants about the conduct of the administrative proceedings, in particular about their initiation, activities performed throughout the selection process and termination. In addition, as mentioned above, each applicant had access to competing applications on an equal basis."
"(67) The concession authority established the selection criteria on the basis of the generally applicable national laws (...) In any event, the concession authority announced and communicated the selection criteria sufficiently in advance so that the applicants had time to clarify any doubts in this respect and to improve their offers before submitting final applications (...). Consequently, the allegation of the Complainant that in the course of a tender DEP could have offered a better quality service in return for the concession is not justified."

"(69) Therefore, the Commission considers that the selection process was conducted in a transparent manner, where all potential participants knew about it and were properly informed and aware of its initiation, the conditions to be selected, the activities performed throughout the selection process and its termination."

\section{c) Non-Discrimination}

According to the Commission, a selection process is non-discriminatory if participants are treated equally and assessed on the basis of objective criteria which are defined in advance.

"(71) The concession authority set and announced the selection criteria sufficiently in advance and communicated them to all the applicants at the same time (...). These criteria were objective, that is to say independent of the content of any of the applications, and were the same for all the applicants. They were not adapted ex-post to favour any of the applications. The concession authority assessed the applications against these criteria and found that KGHM met them best."

Moreover, "(72) the Commission observes that the concession fee for exploration and exploitation is established by means of an objective formula, laid down in Polish law. Any applicant granted the concession would have paid the concession fee calculated on the basis of the same algorithm." "(73) The Commission further stresses that the outcome of the selection process for the award of the exploration rights has led to choosing KGHM, the applicant offering the highest probability of maximising the proceeds accruing to Poland from the possible subsequent exploitation of the areas for which the concession for exploration was awarded. Indeed, among all companies having shown a potential interest, KGHM offered to explore the highest number of different min- 
erals within the widest geographical area". "(74) The concession fee for exploration and for the associated mining usufruct right is a product of a unit price per type of a mineral and the area under concession. Given that KGHM proposed the largest scope of geological works, both in terms of the area concerned and the number of minerals to be explored, by granting the concession for exploration to KGHM, Poland has indeed chosen the applicant that maximised its potential revenue. Given the formula to calculate remuneration of the State for the exploitation rights (...), Poland can reasonably expect the highest revenue from the future exploitation rights from the applicant that proposed to explore the largest area and more minerals than other applicants."

Indeed, since the fee is calculated also on the basis of the size of the area of exploration and size of exploitable minerals, the fee paid by KGHM was certainly the highest. But this complicates issues. Was Poland acting as a regulator or as an economic operator aiming to maximise revenue? The fact that the fee paid by KGHM was the highest should have been irrelevant. What mattered was solely that the same formula was applied to KGHM and that formula was not more favourable to KGHM. At any rate, the Commission concluded that " $(80)$ the selection process was conducted in a non-discriminatory manner."

However, the next section provides a few simple calculations to show that KGHM could have behaved strategically and could have influenced the outcome of the selection process by applying for a larger exploration area, without necessarily being the company that was more efficient in the eventual exploitation of the minerals.

\section{d) Unconditional Process}

According to the Commission, a selection process is unconditional when an applicant is not encumbered by special obligations for the benefit of the public authorities.

The Commission first addressed an argument of DEP that " $(82)$ the selection criteria applied by the concession authority included non-market conditions, such as the scope of geological works and the quantity of geological information, that do not comply with the market economy vendor test."

The Commission's reply was that "(83) in the present case the State acted as a public authority and not as a market operator, therefore the market econ- omy vendor test is not applicable. It is not appropriate to assess whether a market vendor would have applied such criteria as no market vendor could have granted the concession in the first place. In line with case law, the concession authority had a degree of discretion in identifying appropriate selection criteria. In any event, in the present case, the selection criteria applied by the concession authority arose from the general Polish law and were established by the concession authority in exercise of its public authority powers (...). Thus, the Commission observes that the applicants did not have to assume any special obligations (e.g. maintenance or increase of workforce) to obtain the concession and were assessed solely on the basis of the objective selection criteria."

In other words, when the State acts as a market operator any requirement that reduces the value of the concession would result in the granting of State aid. Of course, when the State acts as a regulator it is natural that it would want to impose obligations that are in line with public policy. But the pursuit of public policy objectives must necessarily lead to loss of potential revenue.

On the basis of the above reasoning the Commission found that the process for granting the concession for exploration was conducted in a competitive, transparent, non-discriminatory and unconditional manner, without conferring an economic advantage on KGHM. Since the criteria of Article 107(1) TFEU are cumulative, the Commission could have stopped its analysis at this point. But it also chose to examine the presence or absence of selectivity, probably to protect its decision from being annulled by EU courts in case there was an error of law in its finding that no advantage was obtained by KGHM.

\section{Selectivity}

The Commission concluded its analysis by explaining why even if there was one winner, the selection process did not discriminate against anyone on an ex ante basis. All applicants were treated equally.

"(89) Even if the selection process were considered not to meet all the relevant criteria taken together (i.e. competitiveness, transparency, non-discrimination and un-conditionality), it undoubtedly was nondiscriminatory. The concession authority assessed the applicants on the basis of objective selection cri- 
Table 1

Applying for Exploration in a Wider Area Can Influence the Outcome of the Selection Procedure Even Though a Competitor May Be More Efficient in Extracting Minerals

\begin{tabular}{|c|c|c|}
\hline & Company K & Company D \\
\hline Area of exploration & 105 & 80 \\
\hline Cost of exploration & $\begin{array}{l}\text { i) } 80 \times 1.2=96 \\
\text { ii) } 105 \times 1.2=126\end{array}$ & $\begin{array}{l}\text { i) } 80 \times 1.3=104 \\
\text { ii) } 106 \times 1.3=137.8\end{array}$ \\
\hline Fee for exploration [area x $1 \%$ ] & $\begin{array}{l}\text { i) } 80 \times 0.01=0.80 \\
\text { ii) } 105 \times 0.01=1.05\end{array}$ & $\begin{array}{l}\text { i) } 80 \times 0.01=0.80 \\
\text { ii) } 106 \times 0.01=1.06\end{array}$ \\
\hline Exploitable minerals [area x 1 ] & 80 & 80 \\
\hline Net revenue per unit of mineral & $80 \times 1.63=130.4$ & $80 \times 1.75=140$ \\
\hline Profit & $\begin{array}{l}\text { i) } 130.4-(96+0.80)=33.60 \\
\text { ii) } 130.4-(126+1.05)=3.35\end{array}$ & $\begin{array}{l}\text { i) } 140-(104+0.80)=35.92 \\
\text { ii) } 140-(137.8+1.06)=1.14\end{array}$ \\
\hline Tax on profit $[25 \%]$ & $\begin{array}{l}\text { i) } 33.60 \times 0.25=8.40 \\
\text { ii) } 3.35 \times 0.25=0.84\end{array}$ & $\begin{array}{l}\text { i) } 35.92 \times 0.25=8.98 \\
\text { ii) } 1.14 \times 0.25=0.29\end{array}$ \\
\hline Total gains for State $[\mathrm{fee}+\operatorname{tax}]$ & $\begin{array}{l}\text { i) } 0.80+8.40=9.20 \\
\text { ii) } 1.05+3 \cdot 35=4.4\end{array}$ & $\begin{array}{l}\text { i) } 0.80+8.98=\underline{9.78} \\
\text { ii) } 1.06+0.29=1.35\end{array}$ \\
\hline
\end{tabular}

Source: Author's compilation.

teria derived from general law, set sufficiently in advance and applied equally to all applicants (...). Although the concession authority has ultimately granted the concession to one applicant, who best met those criteria, all of the applicants competed on equal terms and had been in the same position throughout the selection process to obtain the concession. Had any of them offered to carry out a larger scope of geological works ensuring more geological information and in a shorter timeframe than KGHM, the concession authority could have chosen such applicant and not KGHM. In the MOL case ${ }^{22}$ the Court ruled that "[a] combination of elements such as that observed by the Commission in the contested decision may be categorised as State aid where the terms of the agreement concluded were proposed selectively by the State to one or more operators rather than on the basis of objective criteria laid down by a text of general application that are applicable to any operator".

22 T-499/10 MOL v Commission [2013] ECLI-592, [66].

\section{The Implications of Strategic Behaviour by Applicants}

At several points in its decision on KGHM, the Commission refers to the "benefits" that could be had by Poland. But it does not really consider whether the chosen selection procedure could maximise revenue for Poland, apart from asserting that the non-discriminatory nature of the procedure enabled Poland to derive more benefits from KGHM. The purpose of this section is to demonstrate that this claim is not true if KGHM acted strategically by applying for exploration in a wider area.

In the example which is shown in Table 1, company $\mathrm{K}$ applies to explore an area of 105 while company D's application covers an area of only 80 because that is where it believes mineral deposits are likely to be found. Company $\mathrm{K}$ exaggerates its claim because this is the criterion used by Poland to award licences (we abstract here from other criteria). Since the process is transparent, company D has a choice. It can State its true intent to explore only 80 [option i)], or can apply for 106 which slightly exceeds the 
quotation of company K [option ii)]. We assume that company $\mathrm{K}$ is more efficient in exploration so that its cost per unit of land that is explored is 1.2, while that of company D is 1.3. Company D is less efficient in exploring. However, company D is more efficient in exploiting the discovered minerals. It earns net revenue of 1.75 per unit of minerals extracted, while company K earns only 1.63.

Although the procedure is transparent, company $\mathrm{K}$, by quoting 105 , makes it impossible for company D to win the concession. If company D quotes 106, it will make profit of only 1.14. If the selection were based solely on the highest monetary offer, company D could outbid company K because K's profit of 33.60 is less than company's D profit of 35.92 [this is the case where the exploration takes place in an area of 80 ]. The government can obtain 4.4 from awarding the contract to company $\mathrm{K}$ but 9.78 from awarding the contract to company D. [To keep the calculations simple, these numbers do not include a possible fee for the exploitation. It is assumed that the licence goes to the company that generates the largest profit which then results in the largest amount of tax revenue for the government].

This simple example demonstrates that when a procedure based on qualitative criteria is used to select a concessionaire who has to exploit commercially an asset it may not succeed to choose the overall most efficient operator who can generate the most revenue (benefits) for the State. Such a procedure is also vulnerable to manipulation by strategic behaviour by competitors.

In this example, company $\mathrm{K}$ can explore at a cost of 1.2 per unit of area and earn net revenue of 1.63. That is, its final profit per unit of exploration and exploitation is 0.43 . Company D has a cost of 1.3 and net revenue of 1.75 , which leads to final profit of 0.45 . The more important lesson that can be drawn from this example is that company D is more efficient in the combined task of exploring and exploiting. The government can obtain more benefits from awarding the contract to D for every unit of area that is explored and exploited.

\section{Conclusions}

The case law is rather clear that when Member States act as regulators, they need not maximise revenue from the granting of permits, licences or concessions rights. However, according to the same case law, when Member States act as regulators, they must grant permits, licences or concession rights on the basis of procedures which are open, transparent, nondiscriminatory and unconditional.

Although allowed by EU law, it is far from obvious how a procedure, that does not take into account the amount of fees that can be paid by candidates, can allocate efficiently the rights to exploit a revenuegenerating asset. This article has shown, with the help of two case studies based on recent Commission decisions, that, first, qualitative selection criteria may not in fact support the effective achievement of the stated regulatory objectives.

Second, a procedure that does not take into account the operators' capacity to generate revenue may end up choosing an operator who is in fact less efficient than its competitors. Not only does such an outcome distort competition, it also fails to maximise benefits for the country.

Since the concept of State aid is objective, a procedure that confers an advantage on certain undertakings and forgoes revenue for the State is likely to constitute State aid regardless of the regulatory aims of the authority that grants the exclusive permits, licences or concessions.

Nothing in EU law prevents Member States from using procedures that can aim simultaneously at the two targets of revenue maximisation and achievement of public policy objectives. 